\title{
EDITORIAL
}

\section{The essence of leadership in health development}

Eight years after the United Nations Millennium Declaration of 2000 [1], most countries in Africa are not on track to achieve the health-related Millennium Development Goals (MDGs) by 2015 [2]. The slow progress has been largely attributed to inability of the national health systems (NHSs) to ethically [3], equitably [4], effectively and efficiently [5] perform their functions of stewardship, health financing, resource/input creation and quality public health services provision to tackle the double burden of communicable and non-communicable diseases. The unsatisfactory performance of NHSs has also been partly attributed to the dearth of national health research systems (NHRSs) capacity [6] to generate and innovatively disseminate [7] pertinent research results needed by public health policy-makers to develop, implement, monitor and evaluate appropriate ameliorative policy interventions.

The performance of NHSs largely hinges on the effectiveness of public health leadership at household, community, district, provincial and national levels. What is leadership? In public health context, leadership is the capability to influence actions and attitudes of other people to achieve specific health development objectives [8] in a dynamic cultural, demographic, epidemiological, technological [9] and socio-economic environment.

What do leaders do? The leaders (i) set direction for health development (i.e. vision and strategies for achieving it); (ii) align followers by communicating the new direction; and (iii) motivate and inspire (capture hearts, minds and souls) followers by satisfying human needs, i.e. physiological needs, safety needs, social needs, esteem/ego needs and self-fulfillment needs [10]; (iv) protect the organization by letting it to feel external pressures within a range it can withstand; (v) provide orientation by challenging current roles and resisting pressure to define new roles quickly; (vi) manage conflict by exposing it or letting it to emerge; and (vii) shape norms by challenging unproductive norms [11].

Who are the public health leaders in Africa? The parents are the first level public health leaders in households. They have a paramount role in assuring household peace, food security (quality and quantity), promotion of healthy life styles, participation in community public health activities, timely seeking of health care, and adherence to prescribed medical dosages. As household public health leaders, parents need to nurture, support, coach and direct their children to develop healthy life styles.

The subsequent levels of public leaders include: the community health workers (CHWs); health center workers; the district hospital health team; the provincial/regional general hospital team; and the tertiary hospital team. Based on analysis of health needs of patients referred from the preceding level of care, the team should formulate a vision and strategies for addressing those needs, and inculcate people at preceding level with public health leadership knowledge and skills and back-up (through support, coaching and giving direction). Every team member is a potential leader as $\mathrm{s} /$ he interacts with other health workers and patients.

The last level is the Ministry of Health Headquarters (MOH/HQ). Based on analysis of health needs of different provinces, MOH/HQ should develop a national health development vision and strategies for addressing those needs. In its leadership role, the $\mathrm{MOH} / \mathrm{HQ}$ should formulate national health policy and strategic health development plan. Therefore, public health leaders are not only the Ministers of health, permanent secretaries, directors of medical services, provincial medical officers of health, district medical officers of health, hospital superintendents and officers-in-charge of health centers but potentially all health workers and parents are also health leaders.

What do the abovementioned public health leaders need to lead? They need power or authority to influence others and achieve their health development vision. Depending on their situation, leaders leverage various sources/points of power [12]: (i) Positional authority, whose scope of command and control hinges on relevant laws, awards and industrial/employment agreements. Those endowed with 
positional power may choose to use coercion (the stick) to deal with undesirable/unacceptable behavior or financial and/or non-financial (e.g. a thank-you/recognition) rewards (the carrot) to shape the attitudes and behaviors of other people. (ii) Knowledge power, which stems from demonstrated competence in essential public health functions. (iii) Personal power, i.e. ability/skills to give assurance to people and make them feel comfortable with the work that needs to be done and the costs involved. (iv) Relationship power, i.e. leverage of good interpersonal working relationships to influence other's behavior. (v) Task power, i.e. a form of authority wielded by people performing a specialized task.

What does it take to be an effective leader? Most effective leaders manifest a high concern for people they are leading and a high concern for achievement of agreed objectives and target, and strive to develop and draw the fullest potential out of every follower. According to Professor Daniel Goleman [13], while the traditional qualities associated with leadership such as intelligence (reasoning, memory, and emotional intelligence), toughness, determination, and vision are necessary for success, they are not sufficient. He argues further "Truly effective leaders are also distinguished by a high degree of emotional intelligence, which includes self-awareness, self-regulation, motivation, empathy, and social skill" (p.1).

Self-awareness means the ability to recognize and understand one's values, goals, moods, emotions, strengths, weaknesses, needs, and drives and their effect on others. Manifestations of selfawareness are self-confidence, realistic self-assessment and self-deprecating sense of humor [13].

Self-regulation is the ability to control or redirect disruptive impulses and moods and the propensity to suspend judgment to think before acting. The signs of self-regulation are trustworthiness and integrity, comfort with ambiguity and openness to change [13].

Motivation is the passion or propensity to pursue goals with energy and persistence for reasons that go beyond money or status. Its hallmarks are strong drive to achieve, optimism (even in the face of failure), and organizational commitment [13]. This is what Professor John P. Kotter refers to as conscientiousness (achievement drive, high energy, initiative) and internal locus of control (optimism, resilience and persistence) [10].

Empathy is the ability to understand the emotional makeup of other people and skill to treat them according to their emotional reactions. It is reflected in expertise in building and retaining talent, crosscultural sensitivity and service to clients [13].

Social skill is the ability to find common ground and build rapport and networks and proficiently manage those relationships. It is manifested in effectiveness in leading change, persuasiveness, and expertise in building and leading teams [13]. Professor John P. Kotter refers to social skill as sociability, i.e. expressive of affection, good listeners, low need to be liked [10].

Since the abovementioned leadership competencies can be learned and improved on, leaders are not born but created. Therefore, there is need for equipping practicing public health workers and students of public health, medical and nursing schools with aforementioned leadership competencies. It is necessary to institutionalize a leadership centered culture within the entire National Health Systems, National Health Research Systems and in curriculums of all institutions that produce human resources for health. Nurturing and encouraging parents and public health workers to play important leadership roles would facilitate the achievement of national and international health development goals and their sustainability.

\section{References}

1. United Nations. Millennium development declaration. Resolution A/55/L.2. New York: UN

2. United Nations Development Programme. The Millennium Development Goals Report 2007. New York: United Nations. 2007; 1-36.

3. Kirigia JM, Wambebe C. Research bioethics committees in the WHO African Region. BMC Medical Ethics 2005, 6:10. This article is available from: [http://www.biomedcentral.com/14726939/6/10]. 
4. Kirigia DG, Kirigia JM. Inequalities in Selected Health-related Millennium Development Goals Indicators in all WHO Member States. African Journal of Health Sciences. 2007; 14: 1-16.

5. Kirigia JM, Asbu EZ, Greene W, Emrouznejad A. Technical efficiency, efficiency change, technical progress and productivity growth in the national health systems of continental African countries. Eastern and Southern Africa Social Science Research Review. 2007; 23: 19-40.

6. Kirigia JM, Wambebe C. Status of national health research systems in ten countries of the WHO African Region. BMC Health Services Research. 2006, 6:135. This article is available from: http://www.biomedcentral.com/1472-6963/6/135

7. Konotey-Ahulu FID. Dissemination of Research Results in Africa. African Journal of Health Sciences. 2007; 14 (1-2): i-iv.

8. http://en.wikipedia.org/wiki/Leadership.

9. Kirigia JM, Seddoh A, Gatwiri D, Lenity HK Muthuri LHK, Seddoh J. E-health: Determinants, opportunities, challenges and the way forward for countries in the WHO African Region. $B M C$ Public Health 2005, 5:137. This article is available from: [http://www.biomedcentral.com/14712458/5/137].

10. Kotter JP. What leaders really do. Harvard Business Review. 1990: 103-111.

11. Heifetz RA, Laurie DL. The work of leadership. Harvard Business Review. 2001: 5-15.

12. Blanchard K, Fowler S, Hawkins L. Self leadership and the one minute manager. London: HarperCollins Publishers; 2005: pp. 43-64.

13. Goleman D. What makes a leader? Harvard Business Review. 2004; 1-11.

Dr Joses Muthuri Kirigia,

Manager, Health Financing and Social Protection Programme,

World Health Organization Regional Office for Africa

Email: kirigiaj@afro.who.int 